\title{
On Effect of Crisis Events on Sinkiang Domestic Tourist Economy
}

\author{
Yang $\mathrm{Bai}^{1,2}$, Deng Feng ${ }^{2}$ \\ ${ }^{1}$ The Tourism College, Xinjiang University, Urumqi, 830046, China \\ ${ }^{2}$ School of economics and management Xinjiang University, Urumqi, 830046, China
}

Keywords: Crisis event, Natural trend curve, Domestic tourist economy, Sinkiang.

\begin{abstract}
The fragile tourism is vulnerable to a variety of crisis events, effect of which becomes a hot issue of tourism research. According to 1995--2014 Sinkiang tourism statistics, this paper will build a background trend line of domestic tourist arrivals and income, and assess the effect of crisis events on Sinkiang domestic tourist economy, in order to provide decision making basis for perfecting tourism crisis forewarning management mechanism.
\end{abstract}

\section{Introduction}

Sinkiang is provided with vast territory, long history, splendid culture, numerous nations, singular folk, and rich tourism resources. According to the census of tourism resources, Sinkiang has 1171tourist attractions, respectively categorized into 67 basic types, accounting for $90.5 \%$ of 74 classification types, and ranking the first in the country. Sinkiang tourism plays an important role in improving people's livelihood and promoting economic development. In recent years, the occurrence of series of crisis events, represented by the financial crisis, epidemic diseases, and violent events, reduced the number of Sinkiang tourists, decreased scenic reception quantity, and depressed travel agencies and hotel operation, leading to the stagnation and retrogression of tourism development in Sinkiang, which has become an important factor restricting tourists to Sinkiang. Therefore, building a mechanism to scientifically and reasonably assess the effect of crisis events on tourism in Sinkiang has important practical significance for promoting sustainable tourism development.

Since the 1990s, with the frequent occurrence of crisis events and their effect on tourist destinations, the effect of crisis events has become the hot issue of research on tourism. Combining with sociology, psychology, management and other aspects, foreign scholars make research on effect of crisis events, and the research content and methods get matured gradually ${ }^{[1-4]}$. Related research in China starts late, and most adopts quantitative models to analyze the effect of crisis events on tourism ${ }^{[5-9]}$. Some scholars explore the effect of crisis events on international tourist economy of Sinkiang ${ }^{[10-12]}$, but currently study on the effect of crisis events on domestic tourist economy of Sinkiang is in absence.

\section{Research Methods}

In 1998, Sun Gennian referenced the concept of environmental background values in environmental science, turned it into dynamic and formed the concept of tourism background trend line ${ }^{[5]}$, reflecting that the destination tourism economic development is resulted from the interaction of local tourism steady growth and cyclical fluctuations. Analysis on the difference between the statistical line and background line can help calculate the effect of crisis events on the tourism economy of destinations. Review "China Tourism Statistics Yearbook", "Sinkiang Statistical Yearbook," collect 1995-2014 Sinkiang tourism statistical data, and on the basis of background trend line of Sinkiang domestic 
tourist arrivals and income, analyze the effect duration and extent of crisis events on Sinkiang domestic tourist economy.

\section{Empirical Analysis}

After thirty years of development, Sinkiang tourism has become the bridge for people to know Sinkiang and a new field for domestic consumption. Especially after the 1990s, Sinkiang tourism sees the rapid development, constant expansion, further optimization of the industrial structure, and product upgrading to increase the added value. Domestic tourist arrivals and revenue increasingly grow, and the status of its pillar industry is gradually consolidated and improved.

From the analysis on 1995-2014 Sinkiang domestic tourist arrivals and income data and its growth rate, it is found that domestic tourist arrivals and income in Sinkiang is in total on the rise, domestic tourist arrivals increasing from 5.14 million in 1995 to 48.0252 million in 2014, and domestic tourist income from 710 million Yuan in 1995 to 61953 million Yuan in 2014, with an average growth rate of $13.06 \%$ and $47.77 \%$, but fluctuation exists in a certain period. In 1995-1998, domestic tourist arrivals increased slowly, and the growth rate is maintained at less than $7 \%$; domestic tourist income in 1998 was 7.2 times than that in 1995, growing rapidly. In 1999-2007, Sinkiang domestic tourist arrivals and income kept growing, with the highest growth rates of $22.7 \%$ and $22.9 \%$ in 2007, but in 2003 there existed a big fluctuation. In 2008-2009, the growth rate of domestic tourist arrivals and income declined sharply, and in 2009, the first negative growth emerged. In 2010, the growth rate of domestic tourist arrivals and income strongly rebounded, reaching a record high of $44.8 \%$ and $59.1 \%$. In 2011-2014, the growth rate of domestic tourist arrivals and income showed a down trend, and negative growth appeared again in 2014. Tourism is susceptible to effect of various crises and therefore forms fluctuations. Such fluctuations reflect the law of the tourism market life cycle, and also result from combined action of various crises.

\section{Buildup of Background Trend Line Model}

According to 1995 - 2014 statistics data of Sinkiang domestic tourist arrivals and income, use Matlab2010b to build the background trend line of Sinkiang domestic tourist arrivals and income (Equation 1 and 2), and correlation coefficients are 0.994 and 0.996, showing the higher degree of model fitting. The background trend line models of domestic tourist arrivals and income are respectively five and nine curve equation, able to be used to calculate the effect of crises on the domestic tourist economy in Sinkiang.

$$
\begin{array}{r}
y_{\text {tourist }}=-64551.6+181439.9 x^{0.5}-163902.9 x+14641.7 x^{1.5}+69096.9 x^{2}-47460.6 x^{2.5}+11556.2 x^{3}+269.3 x^{3.5}-701.5 x^{4}+132.7 x^{4.5}-8.2 x^{5}(1) \\
y_{T I}=-166.7+403.5 x-346 x^{2}+145 x^{3}-33 x^{4}+4.4 x^{5}-0.3 x^{6}+0.02 x^{7}-0.0004 x^{8}+4.4 x^{9}(2)
\end{array}
$$

Wherein, it is the time variable, from 1995 , successively taking $1,2,3, \ldots$.

\section{Data Comparison and Analysis}

According to comparison between the background value and statistic value of Sinkiang domestic tourist arrivals and income, it is found that crises produce effects at varying degree on domestic tourist economy in Sinkiang, such as in 1997-1998, 2003, 2008-2010, and 2014. This paper studies the effect of all previous crisis events on Sinkiang domestic tourist arrivals and income.

Superimposed occurrence of various crises, including public safety incidents occurred in Sinkiang in 1997-1998, Asian financial turmoil from July 1997 to 1998 spreading to Southeast Asia and China, the catastrophic flooding in Yangtze River basin in 1998, has a great effect on Sinkiang demotic tourist economy. According to the comparison between background value and statistical value, it is found that effect of public safety event, financial turmoil and the flood on Sinkiang demotic tourist economy lasts from 1997 to 1999, and cumulative loss of domestic tourist arrivals and income is 649,100 and 1.78 billion Yuan.

From November 2002 to 2003, the global epidemic disease outbreak caused by SARS, rapidly spread to Southeast Asia and even the whole world. Classified as the public health event, to some 
extent, it limits the travel plans of potential tourists. According to the comparison between the background value and statistic value, the effect of SARS on domestic tourist economy in Sinkiang lasts for 1 year. The cumulative loss of domestic tourist arrivals is 315,100, and domestic tourist income loss totaled 536 million Yuan.

In 2008, more than one crisis events occurred one after another, such as freezing rain and snow weather in the southern area, "3 • 14" violent crime in Lhasa , "5.12" earthquake in Wenchuan, the global financial crisis triggered by US subprime mortgage crisis. In addition, security was strengthened against terrorism for 2008 Beijing Olympic Games, and some people chose to watch the game at home or on site, resulting in reduction of tourist arrivals to Sinkiang. Superimposed occurrence of various crisis events has certain impact on domestic tourist economy in Sinkiang. According to the comparison between the background value and statistic value, the effect of a variety of events on the domestic tourist economy in Sinkiang lasts for 1 year. The cumulative loss of domestic tourist arrivals is 140,900, and domestic tourist income loss totaled 480 million Yuan.

Urumqi "7.5" event burst in July 2009 was the most serious violent crime event since the founding of New China, resulting in the most casualties, the most serious property damage and the greatest social effect, having a huge impact on tourism in Sinkiang, and leading to the first negative growth of Sinkiang domestic tourist economy. According to the comparison between the background value and statistic value, the effect of Urumqi "7.5" event on domestic tourist economy lasts from 2009 to 2010. The cumulative loss of domestic tourist arrivals is 7,346,500, and domestic tourist income loss totaled 4271 million Yuan.

Worldwide outbreak of bird flu crisis in 2011--2014 threats the health of visitors, and more violent crime events occurred in Sinkiang threats personal and property safety of tourists. In addition, the central government imposed eight regulations and six prohibitions since December 2012 in the country, which curbed public funds for travel. All of the above events had significant impact on domestic tourist economy in Sinkiang in 2011-2013, but after superposed occurrence in 2014 negative growth of domestic tourist economy appeared again. According to the comparison between the background value and statistic value, the cumulative loss of and domestic arrivals and income caused by above events are respectively 602,400 and 1416 million Yuan.

\section{Conclusions}

Crisis events damage the tourism image of destination, reduce confidence of tourists in the destination, and greatly impact the local tourism. The effect of crisis events on Sinkiang domestic tourist economy is concluded as follows,

On the whole, either global or localized crisis event, either unitary or superposed crisis events, will have a negative impact on Sinkiang domestic tourist economy.

From the time point of view, crisis events in different periods have negative impact at varying degree on the domestic tourist economy in Sinkiang. First it is in 2009-2010 when Urumqi "7.5" violent crime event had a continuous effect; followed by in 1997-1998 when public safety event, Asian financial turmoil, and Yangtze River basin flood occurred one after another; again by in 2014 when violent events and avian flu superimposed and in 2003 when SARS outbroke, and finally in 2008 when freezing rain and snow weather in southern area, "3.14" violent crime in Lhasa, "5.12" earthquake in Wenchuan, and global financial crisis happened one after another.

From the nature of the event, major events and national policy will result in a negative impact on the domestic tourist economy in Sinkiang, such as 2008 Beijing Olympic Games, eight regulations and six prohibitions in 2013.

From the place point of view, the negative impact of crisis events on domestic tourist economy in Sinkiang is greater than that in tourist region; especially violent events will reduce security sense of tourists about Sinkiang as a tourist destination and undermine their tourist image perception.

Western development, fully supporting Sinkiang by 19 provinces and municipalities and Silk Road economic belt construction provide unprecedented opportunities and challenges for tourism 
development in Sinkiang. Faced with the new situation, for crisis events frequently occurring, it is urgent to perfect clearly classified forewarning management mechanism for tourist crises. With the help of new media, establish transparent public information platform, eliminate insecurity sense of tourists about Sinkiang as a tourist destination and set a good tourist image, reduce the negative impact of crises on tourism in Sinkiang, to promote the sustainable tourism development in Sinkiang.

\section{Acknowledgement}

This paper belongs to National Tourism Administration "Thousands of Tourism Excellence Program" Research-based Excellence Training Program (WMYC20151086).

\section{References}

[1] Khan, H. Asian contagion: impact on Singapore tourism, Annals of Tourism Research, 2001, 28(1): 224-226.

[2] Huang, H., Jennifer, C. H. J. Earthquake devastation and recovery in tourism: the Taiwan case, Tourism Management, 2002, 23(2): 145-154.

[3] Barbara, A. Crisis management in the Australian tourism industry : Preparedness, personnel and postscript, Tourism Management, 2006, 27(6): 1290-1297.

[4] Wang, Y. S. The impact of crisis events and macroeconomic activity on Taiwan's international tourism demand, Tourism Management, 2009, 30(1): 75-82.

[5] Sun Gennian. Establishment and Scientific Significance of China Tutbound Tourism Background Trend Line. Geographical Sciences, 1998 (5): 442-448.

[6] Zhu Mingfang, Liu Siming. Application of TRAMO / SEATS in Research on Effect of Crisis Events on Tourism. Journal of Tourism, 2007, 22 (6): 69-74.

[7] Li Feng. Comparative Research on Effect of Tourism Crisis Events Based on Different Nature of Baseline - Taking4 Tourism Crisis Events in China for Example. Tourism Sciences, 2009, 24 (4): 73-78.

[8] Yan Shu, Xiao Jiewen. On Nnconventional Tourism Crisis Effect Path from Perspective of Supply and Demand. Social Sciences, 2010 (5): 69-73.

[9] Zhang Tiesheng, Sun Gennian, Ma Lijun. Evaluation on Effect of Crisis Events on Zhangjiajie Tourism-Based on High Resolution Analysis of Baseline Model. Economic Geography, 2010,32 (10): 145-151.

[10]Xie Xuemei, Sun Gennian, Han Cunxian. Analysis on Effect of Events on Tourism in Sinkiang. Geographical Research, 2010, 27 (1): 65-73.

[11]Wang Songmao, Fang Liangyan, Hai Miti Yimiti. Effect of Major Events on International Tourism in Sinkiang for 20 Years. Arid Land Resources and Environment, 2012,26 (5): 194-198.

[12]Wen Jiang, Xiong Heigang. Spatial Difference Research on Effect of Major Events on International Tourism in Different Regions of Sinkiang. Arid Land Resources and Environment, 2014,28 (1): 163-168. 